\title{
STUDY OF THE EFFECT OF INTRAUMBILICAL VEIN OXYTOCIN INJECTION ON THIRD STAGE OF LABOR
}

\section{BY}

Shimaa m.m. Zaher, Ashraf I. El Mashad, Mohammed f. El Sherbiny, Mohammed E. Mohammed

\section{FROM}

\author{
Obstetrics And Gynecology Faculty Of Medicine Banha University
}

\begin{abstract}
Background:

The principal management of the third stage of labor is aimed at reducing the time of delivery of the placenta, thereby minimizing serious adverse effects such as blood loss and retained placenta. Umbilical vein oxytocin injection directs treatment to the placental bed and uterine wall, resulting in earlier uterine contraction and placental separation
\end{abstract}

\section{Aim of study:}

The present study aimed to evaluate the effect of intraumbilical vein oxytocin on reducing the duration of the third stage of labor and the need for manual delivery of placenta, in comparison with normal saline administration.

Patients and Methods: The present study recruited 300 hundred women indicated for normal labor. They were equally and randomly assigned into one of two groups: GI (the study group) which had intraumbilical oxytocin and GII (control group) which had normal saline infusion.

\section{Results:}

Comparison between the studied groups regarding the demographic data didn't reveal statistically significant differences. In addition, there were no statistically significant differences between the studied groups regarding the obstetrical data. Furthermore, no statistically significant differences were found between the studied groups regarding the preoperative $\mathrm{Hb}$ levels. There was a statistically significant higher blood loss in the control group when compared with the study group. In addition, the study group had significantly higher postoperative $\mathrm{Hb}$ when compared with controls. They were also found to have less Hb difference when compared with controls. It was also shown that that women in the study group had significantly shorter duration of the third stage when compared with women in the control group. Regarding the reported complications in the studied groups, we showed no statistically significant differences between the studied groups regarding the reported complications.

\section{Conclusions:}

Intraumbilical oxytocin resulted in shorter duration of the third stage of labor. It also resulted in less blood loss and less hemoglobin concentration reduction. 


\section{INTRODUCTION}

The third stage of labor is defined as the period of time between delivery of the fetus and delivery of the placenta. The most common complication accompanying this stage is postpartum hemorrhage ( $\mathrm{PPH})$, and prolonged third stage of labor owing to placenta retention and uterine atony are among the underlying cause of most cases of PPH (Habek and Franicević, 2007).

In developed countries, 3-5\% of deliveries are complicated by postpartum hemorrhage; in developing countries, it is $\mathbf{5 0}$ times more common. Retained placenta is another complication of the third stage of labor. It occurs in $0.1-2 \%$ of deliveries and is associated with a high risk of hemorrhage (Weeks, 2008).

At present, treatment is by manual removal of the placenta, which requires an operating room, a surgeon, and an anesthetist, facilities that are often unavailable to women in resource-poor settings. As a result, this condition has a case fatality rate of nearly $10 \%$ in rural communities (Cunnigham et al., 2004).

The duration of the third stage of labor is $5-15 \mathrm{~min}$; however, in 2-5\% of cases, placenta retention occurs and if immediate treatment is not undertaken, these women are at risk of hemorrhage (Nankali et al., 2013).

Although the third stage of labor remains a time of anxiety for obstetricians, actively managing its third stage is now the rule (Puri et al., 2012).

Because a prolonged third stage has been associated with postpartum hemorrhage and the need for manual removal of the placenta, misoprostol and oxytocin (the latter administered intravenously or intramuscularly) have been used to induce uterine contraction. An intravenous bolus of $10 \mathrm{IU}$ of oxytocin has been associated with hypotension, and prolonged infusion has been associated with water intoxication (Cunnigham et al., 2004).

There is a general agreement that oxytocin given either through the intramuscular or intravenous route is effective in reducing postpartum blood loss. However, it is unclear whether the subtle differences between the mode of action of these routes have any effect on maternal and infant outcomes (Oladapo et al., 2012). The intraumbilical route not only appears to avoid adverse systemic effects, but it is useful in women with limited venous access or in whom intravenous fluids should be restricted (Puri et al., 2012).

\section{AIM OF WORK}

The aim of the present study was to evaluate the effect of intraumbilical vein oxytocin on reducing the duration of the third stage of labor and the need for manual delivery of placenta, in comparison with normal saline administration.

\section{PATIENTS AND METHODS}

\section{Study design :}

The present study is a prospective , randomized, double blinded case control study done on 300 women 


\section{Setting:}

Department of Obstetrics and Gynecology, EL-Menshawy general hospital ,Banha university hospital.

Time:

Through the period between December 2014 and December 2018.Ethical oversight was provided

\section{Ethicl consideration:}

The approval of the study protocol was acquired from Ethics Committee of the Department of Obstetrics and Gynecology, and each participant gave a written wellinformed consent before the commencement of the study and every participant had a right to be withdrawn from the study at any time.

\section{Patients' selection:}

The study was conducted on 300 ladies underwent vaginal delivery and accomplished the following inclusion and exclusion criteria. Inclusion criteria

Women with singleton pregnancy, beyond 37 weeks of gestation to 41 weeks, with a living fetus and cephalic presentation, neonatal birth weight of $2500-4500 \mathrm{~g}$, parity between one and five, maternal age younger than 35 years, who underwent normal delivery.

\section{Exclusion criteria}

History of previous $\mathrm{PPH}$, history of cesarean section, any uterine scar, antepartum hemorrhage, placental separation, placenta previa, prolonged labor $(>20 \mathrm{~h})$, accelerated labor $(<3 \mathrm{~h})$, multiple gestations, Polyhydramnios, Chorioamnionitis and instrumental delivery (forceps and vacuum) Moreover, pregnant women who took anticoagulants, or those with thrombocytopenia and the women who underwent painless labor with epidural anesthesia were also excluded.

\section{Methods}

All participants were subjected to the following:

A. Careful history taking: including medical , obstetric history,family history.and menstrual history

B. Thorough clinical and obstetrical examination.

C. Management of the third stage:

Third stage of labour The third stage of labor is defined as the period of time between delivery of the fetus and delivery of the placenta. The most common complication accompanying this stage is postpartum hemorrhage (PPH), and prolonged third stage of labor owing to placenta retention and uterine atony are among the underlying cause of most cases of PPH (Habek and Franicević, 2007).

\section{Method of delivery of placenta in the study according to protocol of our hospital:}

-Umbilical cord clamping : Active management routinely involves clamping of the umbilical cord 
-Uterine contraction : The third stage of labor was actively managed in the two groups by infusion of $20 \mathrm{IU}$ oxytocin in $1 \mathrm{~L}$ Ringer's lactate solution at a rate of $100 \mathrm{~mL} / \mathrm{min}$, immediately after delivery of the fetus.in the study group, $10 \mathrm{IU}(1 \mathrm{~mL})$ oxytocin was injected using a $3 \mathrm{ml}$ syringe at the most proximal site to the placenta after clamping and cutting of the umbilical. in the control group, normal saline was injected into the umbilical vein at the same sit.

\section{-Cord traction:}

Controlled cord traction (CCT) consists of pulling on the umbilical cord while applying counter pressure to help deliver the placenta. It may be uncomfortable for the mother. Its performance requires specific training. Premature cord traction can pull the placenta before it has naturally detached from the uterine wall, resulting in hemorrhage. Controlled cord traction requires the immediate clamping of the umbilical cord .

The pads used for mopping the spilled blood were weighted before and after use. The weight before and after use was measured by means of a spring balance ( weighting device that utilize $s$ the relation between the applied load and the deformation of spring )and recorded. The volume of blood lost was calculated assuming that $1 \mathrm{~g}$ was equivalent to $1 \mathrm{~mL}$.

Study (Oxytocin) group: all participants underwent umbilical vein injection of 20 I.U. Oxytocin diluted in $30 \mathrm{ml}$ normal saline. The injection was performed into the umbilical vein $1 \mathrm{~cm}$ from the introitus proximal to the cord clamp. After injection, the umbilical cord was milked in the direction of the placenta to ensure drug delivery to the placenta.

Control (Saline) group: all participants underwent umbilical vein injection of 30 $\mathrm{ml}$ normal saline. The value of the control group was to investigate if placental expulsion is due to the oxytocin, or to the fluid bolus injection into the umbilical vein

When signs of placental separation reported, the placenta was delivered by Brandt Andrew method with controlled cord traction.

Collected data were documented in the study collection sheets either preoperatively and postoperatively by the operating surgeon and completed by residents

\section{Outcome measures}

For each participant, the duration of the third stage of labor (the time period between the delivery of the fetus and the delivery of the placenta) was recorded. The two groups were compared in terms of the duration of the third stage of labor, hemoglobin $(\mathrm{Hb})$ difference before and $6 \mathrm{~h}$ after delivery, mean decrease in Hb level, and the need for manual delivery of the placenta.

\section{Statistical analysis}

Data obtained from the present study were computed using SPSS versions 17 under the platform of Microsoft Windows XP, Professional Edition. Continuous data were expressed in the form of mean \pm SD while categorical data were expressed in the form of count and percent. Comparison of continuous data were performed utilizing student $\mathrm{t}$ test, while categorical data were done using Chi-square test. $\mathrm{P}$ value less than 0.05 was considered statistically significant. In the study there is no statistically significant correlations between blood loss and the clinical data. 


\section{RESULTS}

Results of the present study are shown in the following

Table-1 Comparison between the studied groups regarding the demographic and obstetrical data

\begin{tabular}{|c|c|c|c|c|}
\hline & \multirow{2}{*}{$\begin{array}{l}\text { Study } \\
(n=150)\end{array}$} & \multirow{2}{*}{$\begin{array}{l}\text { Control } \\
(n=150)\end{array}$} & \multicolumn{2}{|c|}{ Student $\mathrm{t}$ test } \\
\hline & & & $\mathbf{t}$ & $\mathbf{p}$ \\
\hline Age(years) & $28.6 \pm 2.6$ & $28.1 \pm 3.0$ & 1.49 & 0.14 \\
\hline BMI(Kg\M & $27.9 \pm 2.9$ & $27.0 \pm 2.8$ & 1.67 & 0.11 \\
\hline Gestational age(weeks) & $37.9 \pm 1.8$ & $37.6 \pm 1.6$ & 1.14 & 0.25 \\
\hline Gravidity & $2.3 \pm 1.4$ & $2.2 \pm 1.2$ & 0.52 & 0.59 \\
\hline Parity & $1.3 \pm 1.4$ & $1.2 \pm 1.2$ & 0.52 & 0.59 \\
\hline $\begin{array}{l}\text { Location of placenta } \\
\text { Anterior } \\
\text { Posterior } \\
\text { Fundal }\end{array}$ & $\begin{array}{l}52(35.1) \\
45(29.3) \\
53(35.6)\end{array}$ & $\begin{array}{l}65(41.1) \\
46(27.1) \\
46(31.9)\end{array}$ & .43 & 0.45 \\
\hline Induction of labour & $29(9.3)$ & $33(11.1)$ & .59 & .62 \\
\hline Augmentation of labour & 104(77.6) & $93(71.5)$ & .19 & .17 \\
\hline $\begin{array}{l}\text { Spontinous labour } \\
\text { Epidural analgesia }\end{array}$ & $\begin{array}{c}17 \\
0\end{array}$ & $\begin{array}{c}24 \\
0\end{array}$ & & \\
\hline Birth weight & $3435 \pm 359$ & $3400 \pm 350$ & .52 & .56 \\
\hline Preoperativehemoglobin level & $11.2 \pm 0.7$ & $11.2 \pm 0.9$ & .16 & .87 \\
\hline
\end{tabular}

Note: Data presented as mean \pm SD BMI: Body mass index

This table shows no statistically significant differences between the studied groups regarding age and BMI. Augmentation of labour, Birth weight ,Preoperative hemoglobin Also, there is no statistically significant differences between the studied groups regarding gestational age, gravidity and parity.

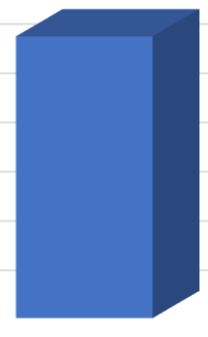

Study

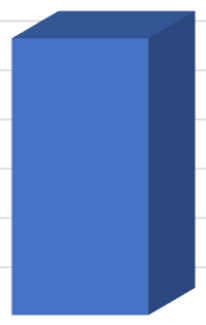

Contro

Fig. (2) Age distribution in the studied groups 


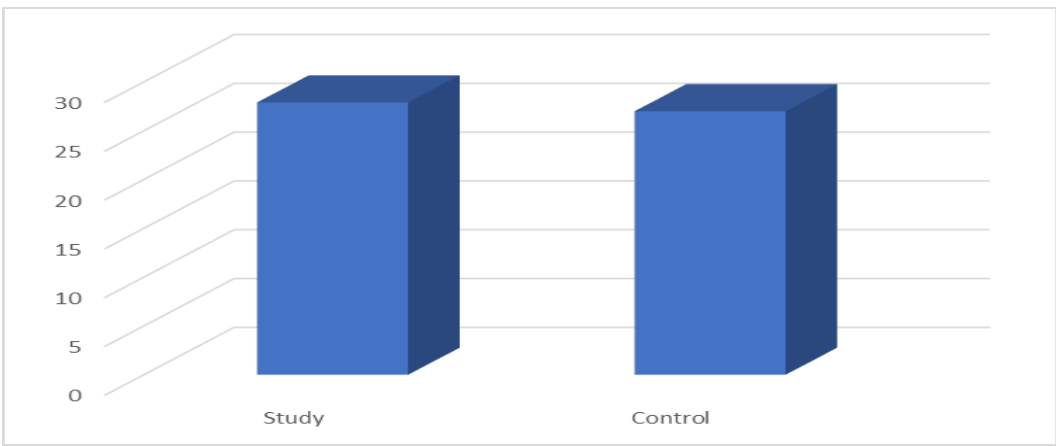

Fig. (3) BMI in the studied groups

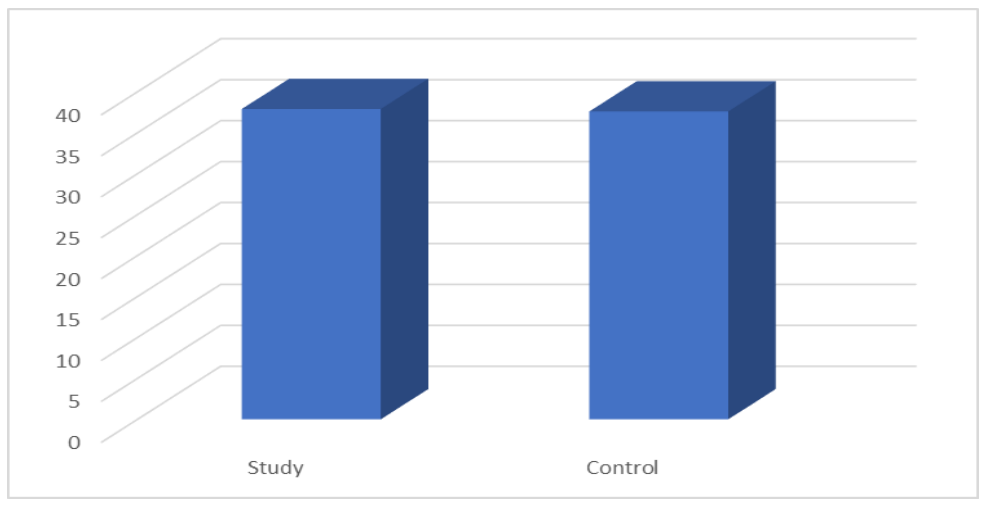

Fig. (4) Gestational age in the studied groups

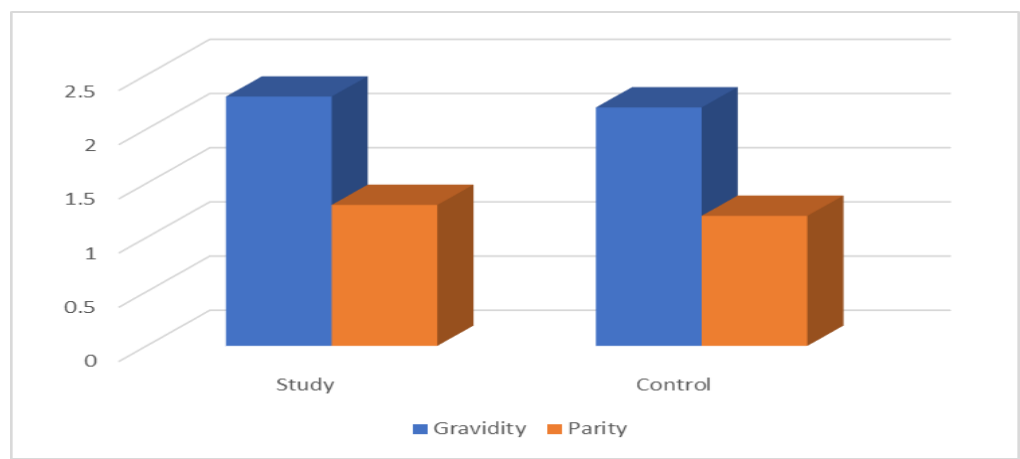

Fig. (5) Gravidity and parity in the studied groups

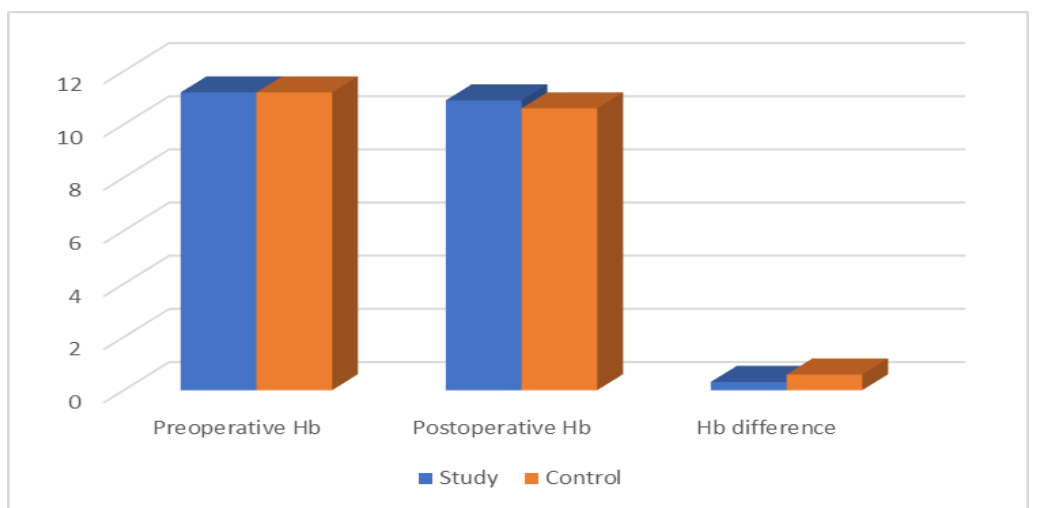

Fig. (6) Comparison between the studied groups regarding preoperative and postoperative $\mathrm{Hb}$ levels and the difference between them. 
Table-2 Comparison of the Oxytocin group and Saline group regards the outcome measures

\begin{tabular}{|l|c|c|c|c|}
\hline & \multirow{2}{*}{ Study $(\mathbf{n = 1 5 0})$} & \multirow{2}{*}{$\begin{array}{c}\text { Control } \\
(\mathbf{n = 1 5 0})\end{array}$} & \multicolumn{2}{|c|}{ Student t test } \\
\cline { 4 - 5 } & & $\mathbf{t}$ & $\mathbf{p}$ \\
\hline Blood loss(ml) & $148.0 \pm 42.5$ & $222.3 \pm 38.2$ & -15.9 & $\mathbf{0 . 0 0 0 1} *$ \\
\hline $\begin{array}{l}\text { Duration of third stageof } \\
\text { labour(min) }\end{array}$ & $2.8 \pm 1.5$ & $4.7 \pm 2.6$ & -7.8 & $\mathbf{0 . 0 0 0 1 *}$ \\
\hline $\begin{array}{l}\text { 24hoursPostoperative } \\
\text { Hb(gldl) }\end{array}$ & $10.9 \pm 0.9$ & $10.6 \pm 0.7$ & 3.1 & $\mathbf{0 . 0 0 2 *}$ \\
\hline Hb difference & & & & \\
\hline
\end{tabular}

This table shows a statistically significant higher blood loss in the control group when compared with the study group. The study group had a mean blood loss of $148.0 \pm 42.5$ $\mathrm{ml}$ while in the control group, blood loss was $222.3 \pm 38.2 \mathrm{ml}(\mathrm{p}=0.0001)$ and shows that women in the study group had significantly shorter duration of the third stage $(2.8 \pm$ 1.5 hours) when compared with women in the control group $(4.7 \pm 2.6$ hours $)$ $(\mathrm{p}=0.0001)$.

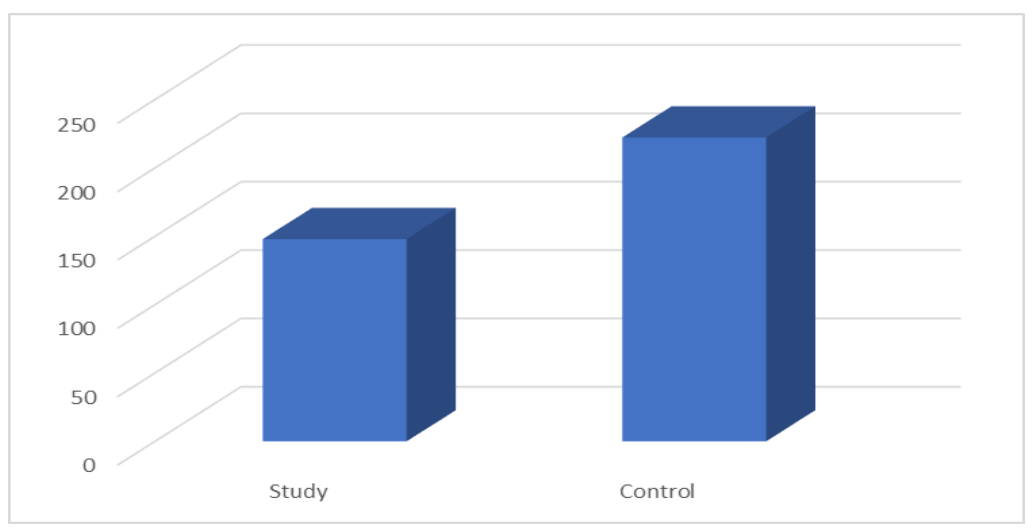

Fig. (7) Comparison between the studied groups regarding blood loss

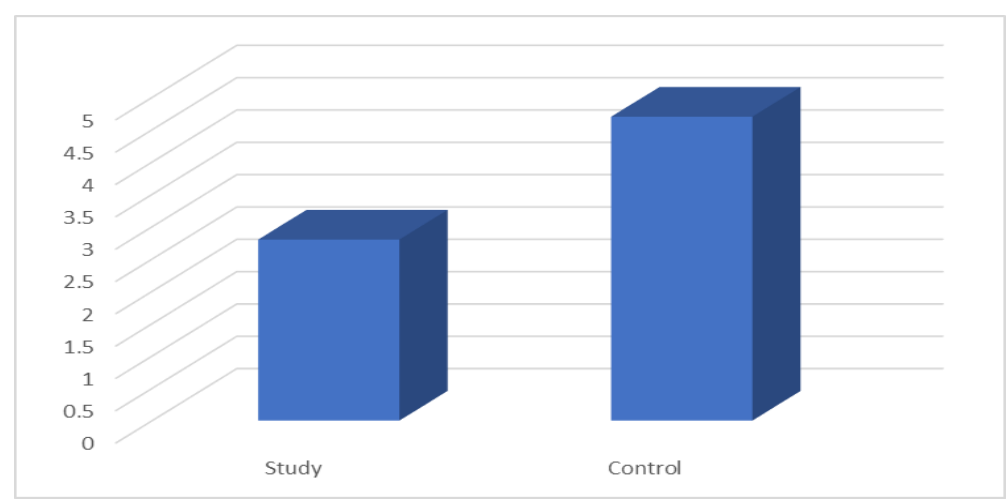

Fig. (8) Comparison between the studied groups regarding third stage duration. 
Table 3Comparison between the studied groups regarding the third stage complications

\begin{tabular}{|c|c|c|c|c|}
\hline & & & Chi-s & re test \\
\hline & $\begin{array}{c}\text { Study } \\
(\mathbf{n}=150)\end{array}$ & $\begin{array}{l}\text { Control } \\
(n=150)\end{array}$ & & \\
\hline & & & $\mathrm{X}^{2}$ & $\mathbf{P}$ \\
\hline Manual removal of the placental & - & $3(2.0 \%)$ & 3.0 & 0.08 \\
\hline Retained placenta & - & $2(1.3 \%)$ & 2.0 & 0.16 \\
\hline Nausea / vomiting & $3(2.0 \%)$ & - & 3.0 & 0.08 \\
\hline
\end{tabular}

This table shows no statistically significant differences between the studied groups regarding the reported complications.

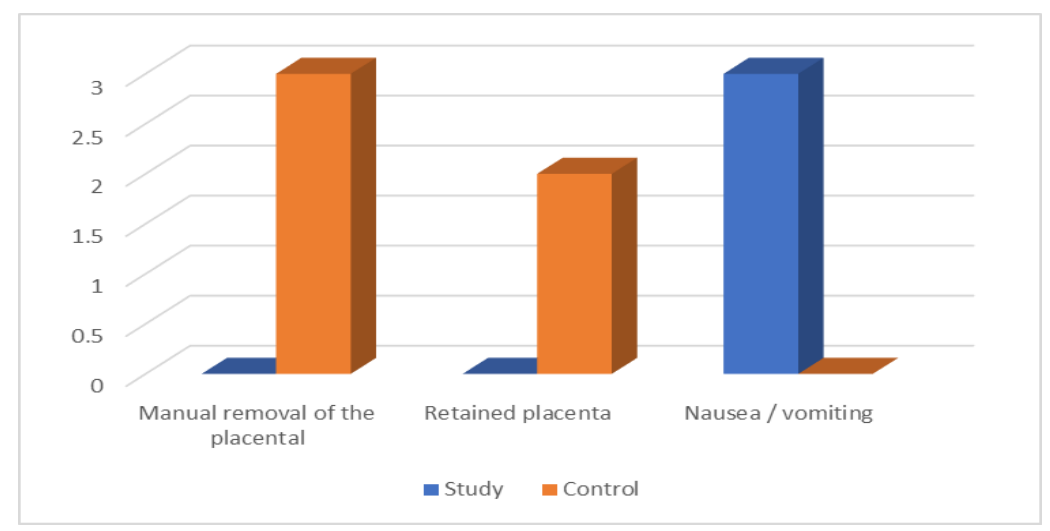

Fig. (9) The reported complications in the studied groups

Table-4 Correlation between third stage duration and clinical data in the study group

\begin{tabular}{|l|c|c|}
\hline \multirow{2}{*}{} & \multicolumn{2}{|c|}{ Pearson's correlation } \\
\cline { 2 - 3 } & $\mathbf{r}$ & $\mathbf{p}$ \\
\hline Age(years) & 0.078 & 0.58 \\
\hline BMI(Kg\m2) & 0.082 & 0.018 \\
\hline Gestational age(Weeks) & 0.059 & 0.68 \\
\hline Gravidity & 0.068 & 0.63 \\
\hline Parity & 0.082 & 0.56 \\
\hline \multirow{2}{*}{ Age } & & $\mathbf{r}$ \\
\hline BMI & 0.036 & $\mathbf{P}$ \\
\hline Gestational age & 0.18 & 0.79 \\
\hline Gravidity & 0.09 & 0.2 \\
\hline Parity & 0.077 & 0.53 \\
\hline
\end{tabular}

Note :correlation is significant at level of 0.05 .

This table shows no statistically significant correlations between $3^{\text {rd }}$ stage duration and the clinical data. 


\section{DISCUSSION}

The third stage of labor is the interval from delivery of the infant to expulsion of the placenta. Delayed separation and expulsion of the placenta is a potentially lifethreatening event because it interferes with normal postpartum contraction of the uterus (Duy and Zheng, 2014).

The degree of blood loss associated with placental separation and delivery depends on how quickly the placenta separates from the uterine wall and how effectively the uterine muscle contracts around the placental bed (where the placenta is attached to the wall of the uterus) and the uterine blood vessels, in addition to how quickly the uterus expels the placenta through the birth canal. Techniques to prevent PPH can target any of these points in placental delivery. A recent review determined that active management of the third stage of labour prevents severe PPH, (defined as $1000 \mathrm{~mL}$ ), when compared to expectant management Retained placenta is used when the placenta is not delivered within one hour after the birth of a baby is a potentially life-threatening complication of the third stage of labour. If untreated, as often happens after a home delivery in developing countries, there is a high risk of maternal death from haemorrhage or infection. The current standard management of retained placenta, by manual removal, aims to prevent these problems, but it is unsatisfactory; it is an advanced skill which requires considerable skill which requires considerable training as well as access to analgesia/anesthesia (World health Organization; 2012)

Intra-umbilical vein Oxytocin injection reducing blood loss during the third stage of labor. This route of administration directs treatment to the placental bed and uterine wall, resulting in earlier uterine contraction and placental separation (Yarivyogev, 2014)

So, the present study aimed to evaluate the effect of intraumbilical vein oxytocin on reducing the duration of the third stage of labor and the need for manual delivery of placenta, in comparison with normal saline administration.

To achieve this target, the present study recruited 3 hundred women indicated for normal labor. They were equally and randomly assigned into one of two groups: GI (the study group) which had intraumbilical oxytocin and GII (control group) which had normal saline infusion.

Comparison between the studied groups regarding the demographic data didn't reveal statistically significant differences. In addition, there were no statistically significant differences between the studied groups regarding the obstetrical data. Furthermore, no statistically significant differences were found between the studied groups regarding the preoperative $\mathrm{Hb}$ levels. These data assures that the postoperative parameters are solely attributed to the protocols used for third stage management.

In the current study, there was a statistically significant higher blood loss in the control group when compared with the study group. The study group had a mean blood loss of $148.0 \pm 42.5 \mathrm{ml}$ while in the control group, blood loss was $222.3 \pm 38.2 \mathrm{ml}$ $(\mathrm{p}=0.0001)$. In addition, the study group had significantly higher postoperative $\mathrm{Hb}$ when compared with controls. They were also found to have less $\mathrm{Hb}$ difference when compared with controls.

This is in agreement with the study of Güngördük et al., (2010) who estimate the efficacy of the routine use of intraumbilical vein injection of oxytocin with active 
management of the third stage of labor in reducing blood loss and length the third stage. In the study of Güng̈̈rdük et al., (2010), randomized, double-blind trial, 412 women undergoing vaginal delivery who did not have risk factors for postpartum hemorrhage were randomly allocated to receive either 20 international units oxytocin diluted with 26 $\mathrm{mL}$ saline $(\mathrm{n}=207)$ or $30 \mathrm{~mL}$ saline $(\mathrm{n}=205)$ by intraumbilical vein injection. Active management of of the third stage of labor (prophylactic injection of 10 international units oxytocin within 2 minutes of birth, early clamping of the umbilical cord, and controlled cord traction) was used in both groups. The primary outcome was mean blood loss during the third and fourth stages of labor. The mean estimated blood loss was significantly lower in women treated with oxytocin compared with women in the placebo group $(195.3 \pm 81.0 \mathrm{~mL}$ compared with $288.3 \pm 134.1 \mathrm{~mL}$, respectively; $\mathrm{P}<.001)$. Also, there was a statically significantly higher postoperative $\mathrm{Hb}$ levels in the oxytocin group when compared with the control group $(10.43 \pm .089$ compared with $10.11 \pm 0.62)$ respectively. They was also found to had less $\mathrm{Hb}$ differences in the study group when compared with control group $(0.31 \pm 0.14$ compared with $0.59 \pm 0.14)$ respectively.

In present study, it was also shown that women in the study group had significantly shorter duration of the third stage when compared with women in the control group. This is in accordance with the study of Nankali et al., (2013). In their study, they aimed to determine whether intraumbilical vein oxytocin injection reduces the need for manual removal of placenta and shortens the third stage of labor, in comparison with placebo. In the study of Nankali et al., (2013) randomized clinical trial, 178 women with singleton pregnancy and normal delivery were studied in 1 year. Immediately after fetus delivery, oxytocin infusion (20 IU/L) was started in both groups. Moreover, $10 \mathrm{IU}$ oxytocin and $1 \mathrm{~mL}$ normal saline were injected into the umbilical vein of women in the experimental and control groups, respectively. They found that women who received intraumbilical vein oxytocin had a shorter third stage of labor as compared with the placebo group (2.8 $\pm 1.5 \mathrm{~min}$ vs. $4.7 \pm 2.6)$.

Regarding the reported complications in the studied groups, we showed no statistically significant differences between the studied groups regarding the reported complications. This is in accordance with the former study of Güngördük et al., (2010). However, in the study of Nankali et al., (2013), there was less need for manual delivery of placenta in the experiment group $(1.1 \%$ vs. $5.1 \%)(\mathrm{p}=0.024)$. which was the same for our study and for the study of Güngördük et al., (2010).

There was two cases of the study group show nausea and vomiting and we give her metoclopramide, one case of retained placenta in the study group ,but on the other hand there was two cases of control group needed for manual removal of placenta . Abdominal pain was experienced by study group but the difference was not found statistically significant. No discernible difference was found in the length of hospital stay, the need for blood transfusion, fever and establishment of breast-feeding in both groups.

\section{REFRANCES}

Cunnigham FG, MacDonald PC, Loveno KJ, Gant NF, (2004) Normal Labour and Delivery. In: Cunningham FG, Lenevo KJ, Bloom SL, Hauth JC, Gilstrap III LC, Wenstrom KD, editors. William Obstetrics. 22nd edition. New York: McGraw Hill; 2004. p. 4334. 
Du Y, Ye M, Zheng F.(2014) Active management of the third stage of labor with and without controlled cord traction: a systematic review and meta-analysis of randomized controlled trials. Acta Obstet Gynecol Scand 2014; 93:626.

Gu “ngo “ rdu “k K, Asicioglu O, Besimoglu B, Gu “ngo “rdu “k O,(2010) Using intraumbilical vein injection of oxytocin in routine practice with active management of the third stage of labor: a randomized controlled trial. Obstet Gynecol;116:619e24

Habek D, Franicević D. (2007) Intraumbilical injection of uterotonics for retained placenta. Int J Gynaecol Obstet. Nov;99(2):105-9.

Nankali A, Keshavarzi F, Fakheri T, Zare S, (2013) Effect of intraumbilical vein oxytocin injection on third stage of labor. Taiwan $\mathrm{J}$ Obstet Gynecol. Mar;52(1):57-60.

Oladapo OT, Okusanya BO, Abalos E. (2012)Intramuscular versus intravenous prophylactic oxytocin for the third stage of labour. Cochrane Database Syst Rev. Feb 15;2: CD009332.

Puri M, Taneja P, Gami N, Rehan HS (2012) Effects of different doses of intraumbilical oxytocin on the third stage of labor. Int J Gynaecol Obstet. Sep;118(3):210-2

Weeks A. .(2008) The retained placenta. Best Pract Res Clin Obstet Gynaecol;22:110317.

Weeks AD, Alia G, Vernon G, Namayanja A, (2010) . Umbilical vein oxytocin for the treatment of retained placenta (release study): a double-blind, randomised controlled trial. Lancet;375: 141

World health Organization (2012) Prevention and treatment of postpartum haemorrhage;

Yariv yogev,(2014) Prof. Yariv Yogev Director, Division of obstetrics and delivery, Rabin Medical Center 


\section{دراسة تأثير حقن مادة الأوكستوسين فى الوريد السري على المرحلة الثالثة من الولادة للسادة الاكاترة شيماء محمد محمد زاهر ، أشرف إسماعيل المشد، محمد فرج الثربينى، محمد إبر اهيم محمد قسم النساء و التوليد كلية الطب - جامعة بنها}

$$
\text { الملخص العربي }
$$

المقدمة :تعرف المرحلة الثالثة من الو لادة بانها الفترة الزمنية مابين ولادة الطفل وو لادة المشيمة وتقدر مدة

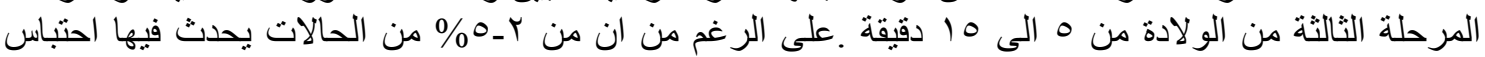

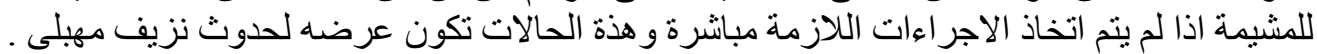

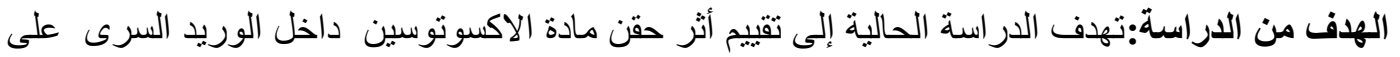

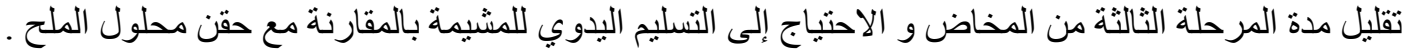

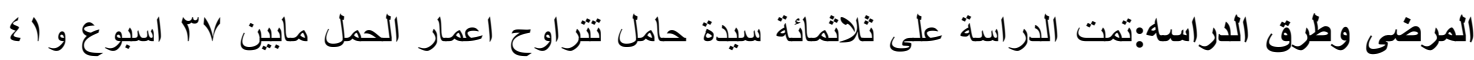

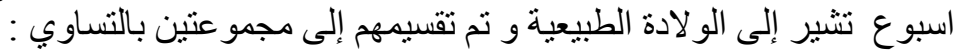

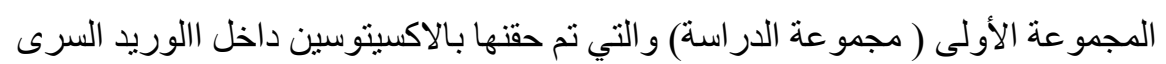

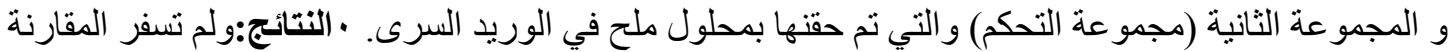

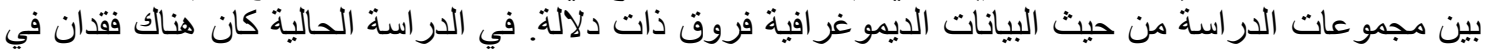

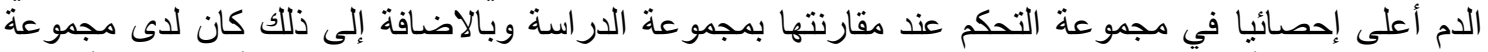

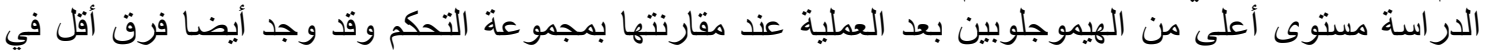

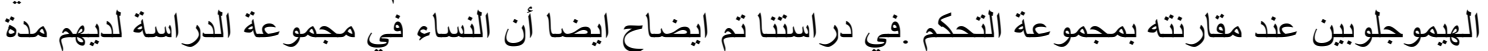

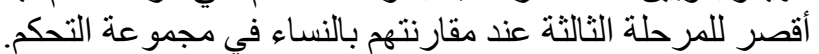
الاستنتاجات:الاكسيتوسين داخل الوريد السرى يؤدي إلى مدة أقصر للمرحلة الثالثة من المخاض.وهو يؤدي أيضا

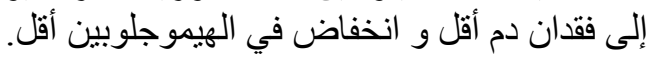

$$
\text { التوصيات }
$$

• يوصى بدر اسة أكبر لتأكيد دور الاكستوسين في إدارة المرحلة الثالثة.

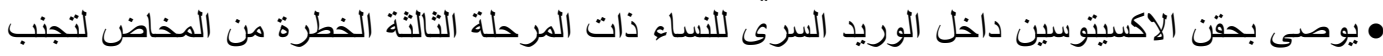
المخاض الطويل و المزيد من فقدان الدم. 